\title{
A COMPARISON OF THE EFFECTS OF AMPICILLIN ON ESCHERICHIA COLI AND PROTEUS MIRABILIS
}

\author{
D. GReENWOOd AND F. O'Grady \\ Department of Bacteriology, St Bartholomew's Hospital, London
}

\section{Plates XXXII and XXXIII}

THE commonest cause of acute urinary tract infection is Escherichia coli; this organism and Proteus mirabilis account for almost all the cases seen in domiciliary practice. When conventional sensitivity testing methods are used, both often appear to be very sensitive in vitro to ampicillin. It has been claimed that the action of ampicillin is independent of the concentration of organisms (Rolinson and Stevens, 1961; Boman and Eriksson, 1963), but bladder urine frequently contains a fully grown or near fully grown culture with more than $10^{8}$ organisms per $\mathrm{ml}$, and it has previously been shown that the resistance of such cultures to ampicillin may substantially exceed that of conventional " large inocula " (O'Grady and Cattell, 1966; O'Grady and Pennington, 1967).

Growth-inhibitory effects of antibacterial agents cannot be satisfactorily tested against high concentrations of organisms by conventional methods, particularly if the cultures are already near their maximal growth. The ability of the organisms to grow in the presence of the agent can, however, be revealed by dilution. If an antibacterial agent is added to a culture in sufficient concentration to inhibit its growth, and the culture is then diluted at a constant rate, the reciprocal opacity of the culture will plot against time as a straight line. If, however, growth is not inhibited, the reciprocal opacity will turn towards the abscissa in proportion to the rate of growth (O'Grady and Pennington, 1967).

Using this method, we set out to examine the quantitative relation between the concentration of organisms and the minimum inhibitory concentration (MIC) of ampicillin. In the course of these experiments, it was found that the behaviour of Pr. mirabilis and E. coli differed materially, and that systematic differences occurred between strains of Pr. mirabilis. It is these differences that we now report.

\section{MATERIALS AND METHODS}

Twelve strains of $E$. coli and 14 strains of Pr. mirabilis (including 5 non-spreading variants) were collected at random from infected urines examined in the routine diagnostic hospital laboratory.

The MIC of ampicillin for each strain was estimated by a conventional doubling-dilution tube titration technique.

Numbers of persisters were estimated by subculturing the tubes after overnight incubation on agar plates with a standard wire-loop delivering $0.001 \mathrm{ml}$.

Received 13 Feb. 1969; accepted 14 Apr. 1969.

J. MED. MICROBTOL.-VOL. 2 (1969) 


\section{Effect of ampicillin in the dilution system}

Overnight broth cultures were diluted 1 in 4 with fresh nutrient broth, and $2 \mathrm{ml}$ of a $1 \mathrm{mg}$ per ml solution of ampicillin were added to $28 \mathrm{ml}$ of the diluted culture (final concentration $=66.6 \mu \mathrm{g}$ per $\mathrm{ml}$ ). This was calculated so that the concentration of ampicillin should not fall below the MIC of the organism during the experiment. The culture was incubated in a flask with a basal tubular prolongation suspended in a transparent waterjacket between the cells of a Spekker photometer (O'Grady and Pennington, 1966). The

TABLE

Number of persisters recovered from 1-ml samples of cultures in broth containing a range of concentrations of ampicillin

\begin{tabular}{|c|c|c|c|c|c|c|c|c|c|c|c|c|c|c|}
\hline \multirow{2}{*}{ Organism } & \multirow{2}{*}{ Strain } & \multirow{2}{*}{$\begin{array}{c}\mathrm{MIC} \\
(\mu \mathrm{g} \\
\text { per ml) }\end{array}$} & \multicolumn{12}{|c|}{$\begin{array}{l}\text { Number of persisters recovered from culture of } 0.001 \mathrm{ml} \\
\text { of material in broth containing ampicillin }(\mu \mathrm{g} \text { per ml) }\end{array}$} \\
\hline & & & 100050 & 5002 & 2501 & 125 & 62 & 31 & 16 & 8 & 4 & 2 & 1 & 0.5 \\
\hline Escherichia coli & $\begin{array}{l}1 \\
2 \\
3 \\
4 \\
5 \\
6\end{array}$ & $\begin{array}{l}4 \\
4 \\
4 \\
8 \\
8 \\
8\end{array}$ & $\begin{array}{ll}0 & 0 \\
0 & 0 \\
0 & 0 \\
0 & 0 \\
0 & 0 \\
0 & 0\end{array}$ & $\begin{array}{l}0 \\
0 \\
0 \\
0 \\
0 \\
0\end{array}$ & $\begin{array}{l}0 \\
0 \\
0 \\
0 \\
0 \\
0\end{array}$ & $\begin{array}{l}0 \\
0 \\
0 \\
0 \\
0 \\
0\end{array}$ & $\begin{array}{l}0 \\
0 \\
0 \\
0 \\
0 \\
0\end{array}$ & $\begin{array}{l}0 \\
0 \\
0 \\
0 \\
0 \\
0\end{array}$ & $\begin{array}{l}0 \\
0 \\
0 \\
0 \\
0 \\
1>\end{array}$ & $\begin{array}{r}0 \\
0 \\
0 \\
0 \\
50 \\
>50\end{array}$ & $\begin{array}{r}0 \\
0 \\
25 \\
\ldots \\
\ldots \\
\ldots\end{array}$ & $\begin{array}{l}\ldots \\
\cdots \\
\ldots \\
\cdots \\
\cdots \\
\cdots\end{array}$ & $\begin{array}{l}\ldots \\
\cdots \\
\cdots \\
\cdots \\
\cdots \\
\cdots\end{array}$ & $\begin{array}{l}\ldots \\
\ldots \\
\ldots \\
\ldots \\
\ldots \\
\ldots\end{array}$ \\
\hline $\begin{array}{l}\text { Proteus mirabilis } \\
\text { (non-swarming) }\end{array}$ & $\begin{array}{l}1 \\
2 \\
3 \\
4 \\
5\end{array}$ & $\begin{array}{l}2 \\
2 \\
2 \\
4 \\
8\end{array}$ & $\begin{array}{ll}0 & 0 \\
0 & 0 \\
0 & 0 \\
0 & 0 \\
0 & 0\end{array}$ & $\begin{array}{l}0 \\
0 \\
0 \\
0 \\
0\end{array}$ & $\begin{array}{l}0 \\
0 \\
0 \\
0 \\
0\end{array}$ & $\begin{array}{l}0 \\
0 \\
0 \\
0 \\
0\end{array}$ & $\begin{array}{l}0 \\
0 \\
0 \\
0 \\
1\end{array}$ & $\begin{array}{l}0 \\
0 \\
1 \\
0 \\
0\end{array}$ & $\begin{array}{r}0 \\
0 \\
12 \\
0 \\
9\end{array}$ & $\begin{array}{c}0 \\
0 \\
20 \\
3 \\
20\end{array}$ & $\begin{array}{r}1 \\
9 \\
>50 \\
4 \\
\ldots\end{array}$ & $\begin{array}{l}11 \\
50 \\
18 \\
\ldots \\
\ldots\end{array}$ & $\begin{array}{l}\ldots \\
\cdots \\
\cdots \\
\cdots \\
\cdots\end{array}$ & $\begin{array}{l}\ldots \\
\ldots \\
\ldots \\
\ldots \\
\ldots\end{array}$ \\
\hline $\begin{array}{l}\text { Proteus mirabilis } \\
\quad \text { (swarming) }\end{array}$ & $\begin{array}{l}1 \\
2 \\
3 \\
4 \\
5 \\
6\end{array}$ & $\begin{array}{l}1 \\
2 \\
2 \\
2 \\
4 \\
4\end{array}$ & $\begin{array}{ll}0 & 2 \\
0 & 0 \\
0 & 0 \\
0 & 0 \\
0 & 1 \\
1 & 0\end{array}$ & $\begin{array}{l}2 \\
0 \\
0 \\
0 \\
1 \\
0\end{array}$ & $\begin{array}{l}2 \\
0 \\
0 \\
2 \\
2 \\
0\end{array}$ & $\begin{array}{l}0 \\
0 \\
1 \\
0 \\
1 \\
0\end{array}$ & $\begin{array}{l}0 \\
0 \\
6 \\
3 \\
4 \\
1\end{array}$ & $\begin{array}{r}0 \\
0 \\
16 \\
7 \\
0 \\
23\end{array}$ & $\begin{array}{r}3 \\
0 \\
16 \\
10 \\
0 \\
4\end{array}$ & $\begin{array}{r}8 \\
0 \\
0 \\
10 \\
0 \\
1\end{array}$ & $\begin{array}{r}30 \\
1 \\
1 \\
12 \\
5 \\
2\end{array}$ & $\begin{array}{r}0 \\
6 \\
4 \\
28 \\
\ldots \\
\cdots\end{array}$ & $\begin{array}{r}>50 \\
\ldots \\
\ldots \\
\ldots \\
\ldots \\
\ldots\end{array}$ & $\begin{array}{l}\ldots \\
\ldots \\
\ldots \\
\ldots \\
\ldots \\
\ldots\end{array}$ \\
\hline
\end{tabular}

$0=$ No persisters found $; \ldots=$ the tube was not subcultured.

culture was constantly mixed and diluted with fresh broth at $1 \mathrm{ml}$ per min. Frequent readings were taken and the results plotted as the reciprocal of the opacity produced by the culture in excess of the value for uninoculated broth. Incubation and dilution were continued for up to $5 \mathrm{hr}$. Subcultures were made at the end of each experiment to check for persisters, possible contaminants, or resistant mutants.

\section{RESULTS}

The MIC of ampicillin for the $E$. coli strains varied between 2 and $16 \mu \mathrm{g}$ per $\mathrm{ml}$; that for Pr. mirabilis (both spreading and non-spreading) between 1 and $4 \mu \mathrm{g}$ per $\mathrm{ml}$. The numbers of persisters recovered from $0.001 \mathrm{ml}$ of each dilution of the selected strains are shown in the table. All the Escherichia strains showed very little survival above the MIC. The Pr. mirabilis strains fell into two groups: most of them showed large numbers of persisters even in high concentrations of 
ampicillin, but the minority group showed a response intermediate between that of Escherichia and the majority of Proteus. The difference was related to swarming: typical swarming strains showed large numbers of persisters and non-swarming strains showed small numbers. This difference between the types was further demonstrated by their behaviour in the dilution system.

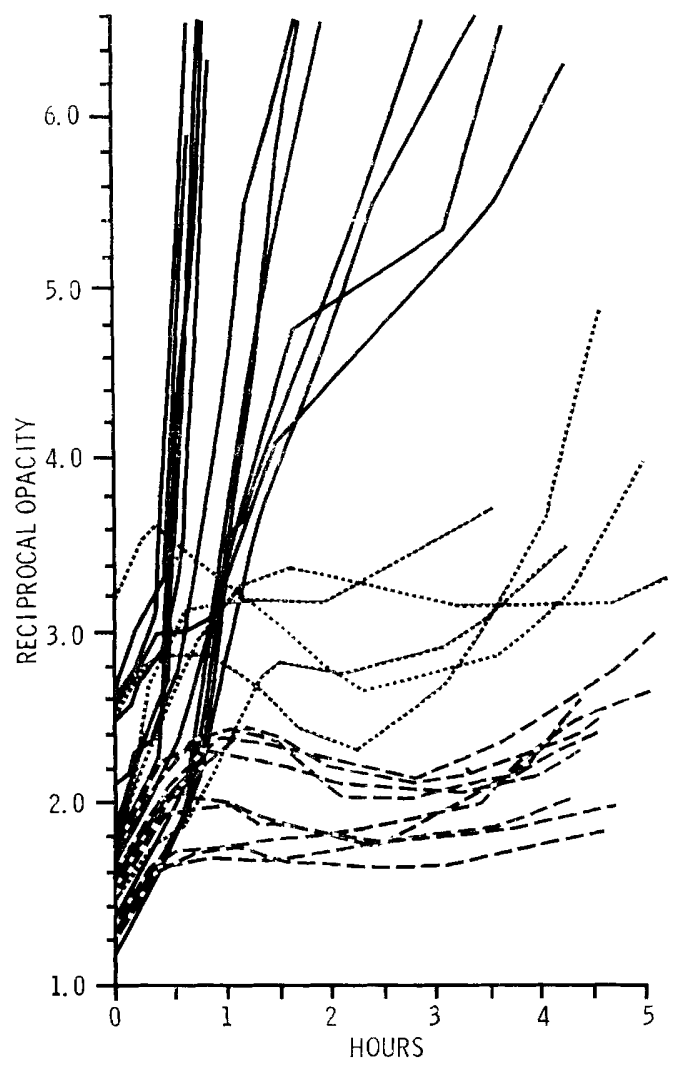

FIG. 1.-Reciprocal opacities of individual strains of E. coli —_ swarming Pr. mirabilis - and non-swarming Pr. mirabilis ampicillin to a final concentration of $66 \mu \mathrm{g}$ per $\mathrm{ml}$.

\section{Findings in the dilution system}

The profoundly different response between $E$. coli and swarming strains of Pr. mirabilis can be seen in fig. 1. E. coli, after an initial period of 20-30 min., was rapidly diluted out, the opacity falling in some cases to that of uninoculated broth within $1 \mathrm{hr}$. Swarming Pr. mirabilis strains, on the other hand, again after an initial phase, tended to increase in turbidity over a period of 2-3 hr before being diluted out more or less slowly. The non-spreading Proteus strains were again grouped in a position midway between the two extremes. The opacity of the Escherichia cultures declined more rapidly than could be 
accounted for by the rate of dilution and it appeared that the difference was probably due to rapid lysis of the organisms.

\section{Effect of ampicillin on different stages of the growth cycle}

Representative strains of E. coli and Pr. mirabilis were inoculated from overnight broth cultures into $25 \mathrm{ml}$ of fresh nutrient broth to give a concentra-

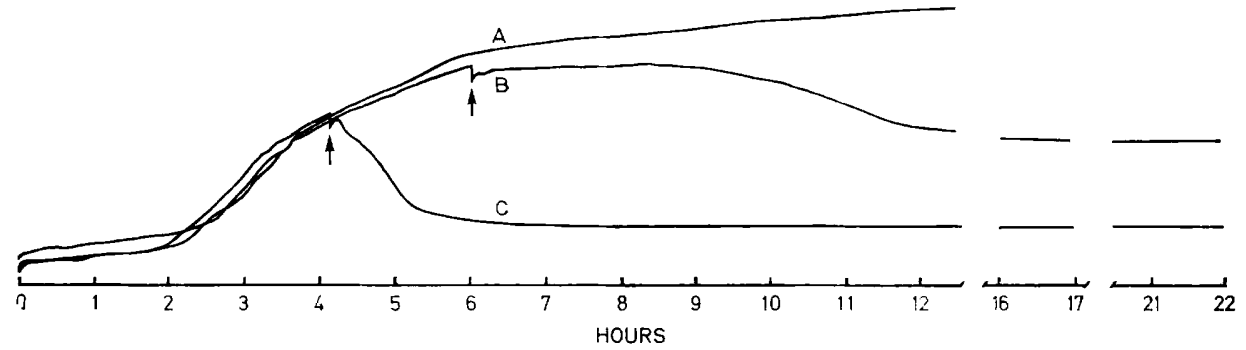

FIG. 2.-Continuous record of growth of E. coli recorded photometrically (A). Rapid lysis on addition of ampicillin ( $100 \mu \mathrm{g}$ per ml final concentration) in mid-logarithmic phase (C) and slow delayed decline on similar addition later in the growth cycle (B). The small drop in opacity is caused by the addition of the solution.

tion of $10^{4-5}$ organisms per $\mathrm{ml}$. The cultures were incubated at $37^{\circ} \mathrm{C}$ in the light path of a photometer connected to a continuous recording system (Watson et al., 1969). Ampicillin was added to a final concentration of $100 \mu \mathrm{g}$ per ml and incubation continued for up to $24 \mathrm{hr}$.
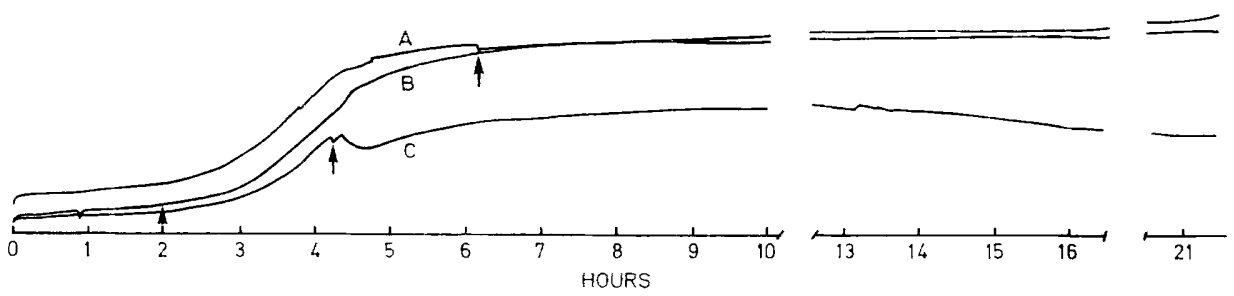

Fig. 3.-Continuous record of swarming Pr. mirabilis (A). There is a transient fall and subsequent increase in opacity before onset of gradual lysis $9 \mathrm{hr}$ after the addition of ampicillin (100 $\mu \mathrm{g}$ per $\mathrm{ml}$ final concentration) in mid-logarithmic phase $(C)$. Similar addition of ampicillin later in the growth cycle had no effect (B).

Addition of ampicillin in the mid-logarithmic phase caused $E$. coli to lyse almost immediately (fig. 2). On similar treatment, a fraction of Pr. mirabilis cells of a swarming strain also appeared to lyse, but this initial response was followed by a prolonged increase in opacity before slow lysis finally ensued (fig. 3).

\section{Morphological studies}

It seemed that such profoundly different behaviour must be accompanied by differences in morphological response, and the dilution experiments were repeated with selected strains representing the different types of response found. 
Samples were removed at intervals into a fixative consisting of 1 per cent. glutaraldehyde containing 5 per cent. sucrose and left for at least $2 \mathrm{hr}$ (usually overnight). After that the suspensions were washed three times with distilled water by light centrifugation. Preparations for light microscopy were air-dried on microscope slides and stained with weak carbol fuchsin. At the same time, air-dried coverslip preparations were " stained" with 5 per cent. ferric chloride for $10 \mathrm{~min}$., washed in two changes of distilled water, and prepared for examination in the Cambridge stereoscan electron microscope by the method described for red blood cells by Salsbury and Clarke (1967).

The already well-documented transformation of Gram-negative bacilli into spheroplasts is illustrated in a swarming strain of Pr. mirabilis in figs. 4 and 5. Fig. 6 shows the stereoscan appearance of the "Hasenform" of Liebermeister and Kellenberger (1956).

It seems, however, that considerably greater damage occurs to the cell wall than simply point-dissolution at the site of spheroplast emergence. Multiple points of emergence, sometimes leading to gross deformity of the cell, were often seen (fig. 7) and cell ghosts were common even where spheroplast formation was well developed (fig. 4).

In the case of $E$. coli very similar morphological changes were encountered, but spheroplast formation was very much less common and the bulk of the organisms showed rapid aggregation and dissolution (fig. 8). What appeared to be penetration injuries of the cells could sometimes be seen; these characteristically occurred terminally or at the probable sites of developing cross-walls (fig. 8). Equally striking was the survival of occasional apparently morphologically normal cells in the midst of wholesale destruction of the rest of the population (fig. 8). Light-microscope pictures taken after 30 minutes' exposure to ampicillin (when spheroplasts were only just beginning to appear) showed marked variation in staining (fig. 9), suggesting disappearance of cell substance to a degree that differed markedly between individual cells. At this time, lysis of the organism was already well under way (figs. 1 and 2).

The response of a non-swarming variant of Pr. mirabilis (fig. 10) was different. Some of the cells first developed a fusiform shape with failure to divide (fig. 11), and some showed a similar appearance with a central swelling giving a "bowtie" appearance. Later the whole population degenerated (fig. 12), ultimately into a continuous plastic mass (fig. 13).

\section{Discussion}

Though E. coli and Pr. mirabilis generally show similar sensitivity to ampicillin, when tested by conventional techniques, there appear to be radical differences in their responses. Non-swarming variants of Pr. mirabilis give an intermediate response. The over-all effects observed are the sum of a whole spectrum of responses, each of which affects the component cells of the different species to a greater or lesser degree. Morphological studies of a limited number of strains suggest that though some cells lyse without preliminary transformation, others transform into spheroplasts, and some remain apparently unaffected. 
Thus, though some $E$. coli strains lyse extremely rapidly once exponential growth is induced, part of the population transforms into spheroplasts. The results with $E$. coli (fig. 1) show three distinct groupings, and this may be a quantitative indication of the proportion of cells undergoing transformation into the spheroplast form in the various strains. Again, although spheroplast formation appears to be the chief response of Pr. mirabilis, significant numbers of cells undergo rapid lysis when ampicillin is added in the mid-logarithmic phase. This corresponds to the findings of Liebermeister and Kellenberger, who, using Pr. vulgaris and penicillin, found the time of adding the penicillin critical for spheroplast formation.

In addition to the classical picture of metamorphosis of $E$. coli and Pr. mirabilis into spheroplasts under the influence of penicillins, we have observed the production of multiple cell-wall lesions and, in the single strain of non-swarming Pr. mirabilis so far examined, the reduction of aggregates of organisms to a homogeneous (and presumably non-viable) pulp. This change, which involves far more of the population than are engaged in spheroplast formation, and the very rapid onset of lysis in E. coli (fig. 2) does not support the view that lysis by penicillins is brought about solely by destruction of osmotically sensitive spheroplasts liberated through defects in the cell wall.

The remarkable advances made in recent years in the biochemical analysis of the modes of action of antibiotics (Newton and Reynolds, 1966) emphasise similarities both in the sites of action of dissimilar agents (for example, chloramphenicol, erythromycin and lincomycin) and in the biochemical lesion produced by a given agent in different species. As a result, outstanding differences in antimicrobial activity have tended to be overshadowed. For example, despite the apparent identity of the biochemical defect induced by chloramphenicol and lincomycin, the antimicrobial range of the two agents is vastly different. Still more intriguing than differences between species, or even within species, are those existing within the bacterial population itself. Bigger (1944) first drew attention to the presence of a minority of insusceptible cells in populations of penicillin-sensitive staphylococci. Spheroplast formation has provided a ready explanation for the survival of organisms in the presence of cell-wall inhibiting agents, but intra-population differences in susceptibility to antibacterial agents are too general to be wholly accounted for in this way.

In a recent morphological study (Greenwood and O'Grady, 1969), we showed that streptococci exposed to ampicillin exhibited marked differences in the degree of damage suffered by adjacent cocci in the chain. The present experiments show, within the small compass of an electron-microscope field, cells that after exposure to ampicillin, range from near-normal to totally destroyed. The representation of lethal and non-lethal effects within the spectrum of responses induced by the agent evidently differed both between species (of apparently similar sensitivity) and within the species. The intraspecies difference was clear enough in the case of Pr. mirabilis. The variation in the lytic response to ampicillin suggests that such differences may also exist amongst strains of $E$. coli. 


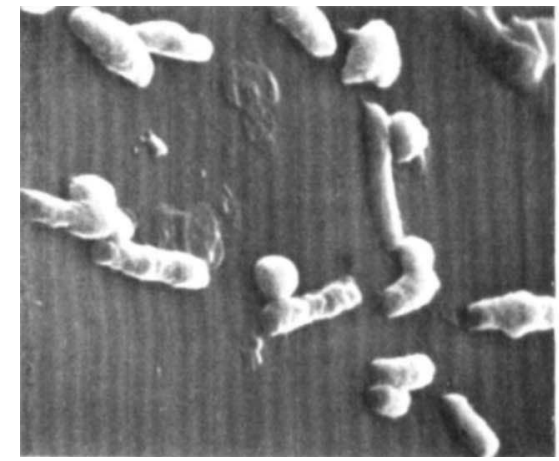

FIG. 4.-A strain of swarming Pr. mirabilis after 60 minutes' exposure to ampicillin in the dilution system, showing emergent spheroplasts, abnormal bulges in the central portion of some cells, cell ghosts and at least one apparently unaffected cell. Electroscan micrograph (ESM). $\times 6700$.

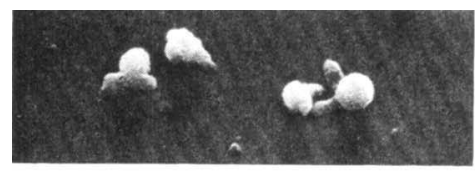

FIG. 6.-The same strain of Pr. mirabilis also after 60 minutes' exposure showing the "Hasenform " of Liebermeister and Kellenberger. ESM. $\times 3200$.

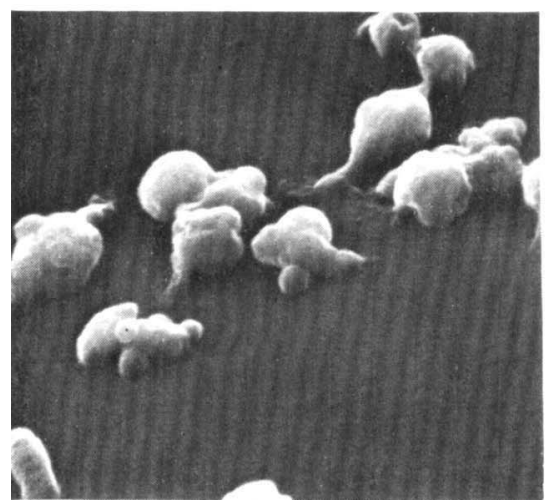

FIG. 7.- The same strain of Pr. mirabilis after 120 minutes' exposure to ampicillin in the dilution system. Spheroplast formation is well advanced and some cells show multiple cell-wall lesions. Apparently unaffected cells are still to be found (bottom left). ESM. $\times 7400$.

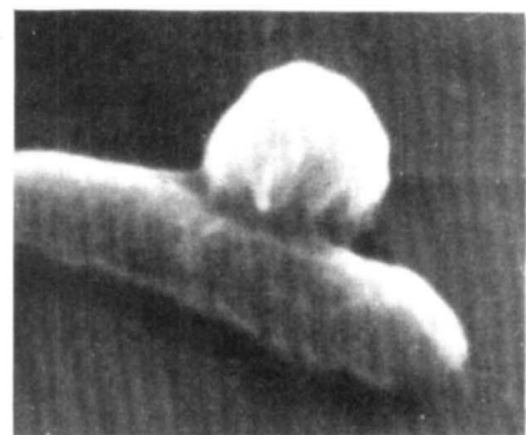

FIG. 5.- The same strain of $P r$ mirabilis, showing emergent spheroplast. ESM. $\times 24,000$.

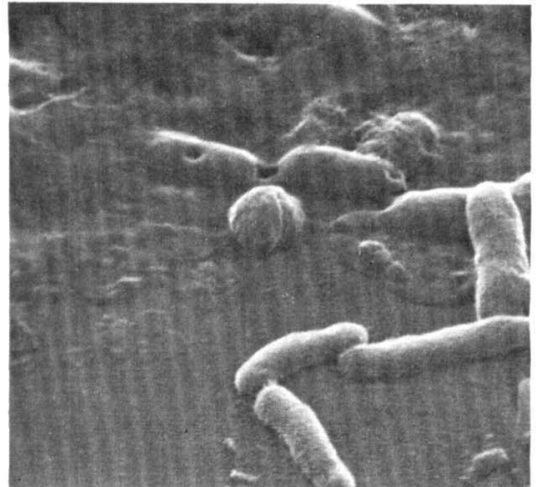

FIG. 8.-A strain of $E$. coli after 60 minutes' exposure to ampicillin in the dilution system. There is a large amount of cellular debris. Central and terminal cell-wall lesions can be seen in the centre of the picture, and in the lower part cells that may be unaffected, or are forming the filaments common in sublethal concentrations of ampicillin. ESM. $\times 10,700$. 
EFFECTS OF AMPICILLIN ON ESCHERICHIA AND PROTEUS

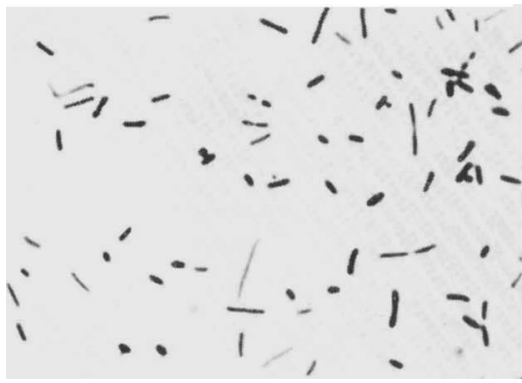

FIG. 9.--The appearance by light microscopy of the same strain as in fig. 8 after 30 minutes' exposure to ampicillin. Filament formation and some emergent spheroplasts are seen, but there is much irregularity of staining suggestive of general loss of substance in many cells. Carbol fuchsin. $\times 1070$.
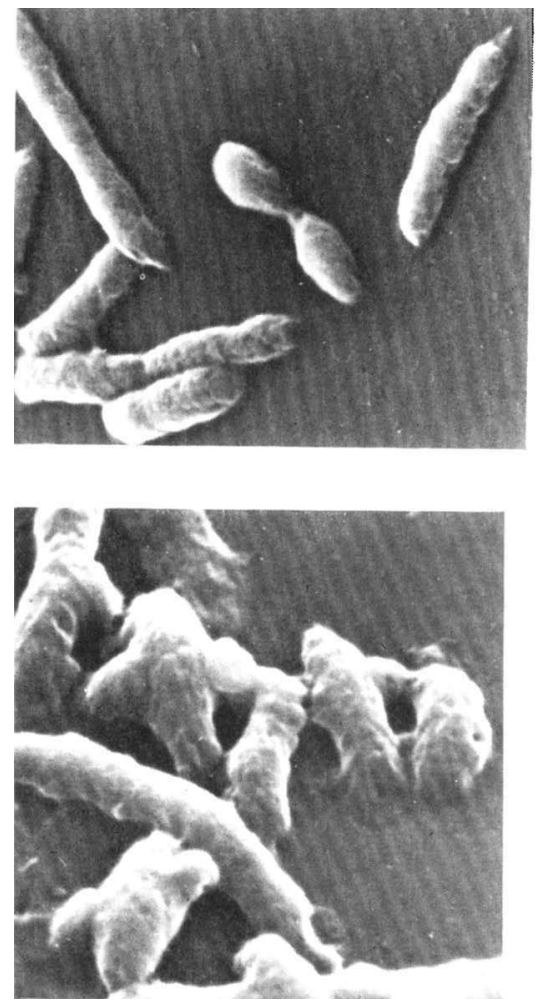

Fig. 12.-The same strain after 120 minutes' exposure. The cell walls appear to be undergoing general dissolution. ESM. $\times 10,700$.

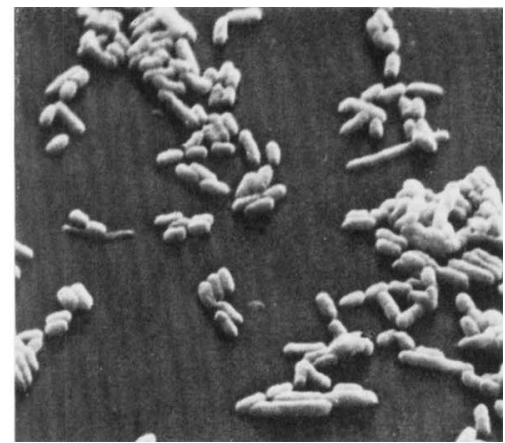

FIG. 10.-A strain of non-swarming Pr. mirabilis before exposure to antibiotic. Swarming strains and $E$. coli show a generally similar appearance. The resolution $(200 \AA)$ is insufficient to show flagella or other surface structures. ESM. $\times 2000$.

FIG. 11.-The same non-swarming strain after exposure to ampicillin in the dilution system for $60 \mathrm{~min}$. showing the typical fusiform deformity. ESM. $\times 8000$.

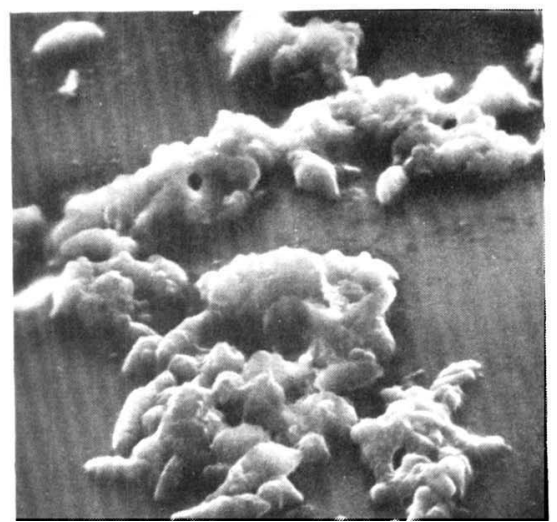

FIG. 13.--The same strain after 140 minutes exposure. The cells are aggregated into masses, which are degenerating into a homogeneous pulp. ESM. $\times 2700$. 


\section{SUMMARY}

Strains of Escherichia coli and Proteus mirabilis that appeared to have similar sensitivity to ampicillin when tested by conventional techniques, behaved differently when dense cultures were exposed to ampicillin and opacity readings were taken. These differences were accompanied by distinctive morphological changes revealed by the stereoscan electron microscope. The morphological changes and the very rapid fall in opacity of Escherichia on exposure to ampicillin suggest that lysis of enterobacteria by penicillins is not wholly due to destruction of osmotically sensitive spheroplasts liberated through defects in the cell wall.

The response of non-swarming strains of Proteus mirabilis to the drug differed from that of swarming strains. The pattern of opacity change was intermediate between that of swarming strains and Escherichia and the morphological response was distinctive.

Morphological evidence is presented of differences in the susceptibility of individual cells within a bacterial population. It is suggested that such intrapopulation differences in various lethal and non-lethal effects may account for the observed differences in response to ampicillin.

We are indebted to Dr J. A. Clarke and Dr A. J. Salsbury of St Bartholomew's Hospital and to the Cambridge Instrument Company for the opportunity to examine morphological changes with the Stereoscan Electron Microscope.

\section{REFERENCES}

BigGer, J. W. . . . . . . . . 1944. Lancet, 2, 497.

Boman, H. G., and Eriksson, Kerstin G. 1963. J. Gen. Microbiol., 31, 339.

Greenwood, D., AND O'Grady, F. . . 1969. Science, N.Y., 163, 1076.

Liebermeister, K., AND KellenBERGer, 1956. Z. Naturforsch., 11B, 200.

E.

Newton, B. A., AND Reynolds, P. E. . 1966. Biochemical studies of antimicrobial drugs, Cambridge.

O'Grady, F., and Cattell, W. R. . . 1966. Br. J. Urol., 38, 156.

O'Grady, F., And Pennington, J. H. . 1966. Br. J. Exp. Path., 47, 152.

" " " , " . . 1967. Br. Med.J., 1, 403.

Rolinson, G. N., AND SteVens, SHIRley 1961. Ibid., 2, 191.

Salsbury, A. J., And Clarke, J. A. . . 1967. J. Clin. Path., 20, 603.

Watson, B. W., Gauci, C. L., Blache, 1969. Physics Med. Biol., 14, 555.

L., AND O'Grady, F. 